\title{
3 Research Square

\section{A new ultra-high throughput screening technique detects human glycans degradation pathways in IBD}

\author{
Alexandra S. Tauzin \\ Mariana Rangel Pereira \\ Liisa D. Van Vliet \\ Pierre-Yves Colin \\ Elisabeth Laville \\ Jeremy Esque \\ Sandrine Laguerre \\ Bernard Henrissat \\ Nicolas Terrapon \\ Vincent Lombard \\ Marion Leclerc \\ Joël Doré \\ Florian Hollfelder \\ Gabrielle Potocki-Veronese
}

\section{Video Byte}

Keywords: Microbiome, functional metagenomics, droplet microfluidics, human gut microbiota, human glycans, beta-N-acetyl-galactosaminidase, IBD, inflammatory bowel disease, method

Posted Date: November 12th, 2020

DOI: https://doi.org/10.21203/rs.3.rs-106705/v1

License: (c) (i) This work is licensed under a Creative Commons Attribution 4.0 International License. Read Full License 


\section{Abstract}

Worldwide incidences of inflammatory bowel disease (IBD), including Crohn's disease and ulcerative colitis, are on the rise. In IBD, the mucus layer that separates the intestine from gut bacteria wears thin, creating the opportunity for microbial invasion. Understanding how bacteria behave at this critical junction could offer clues on how to combat IBD. But current exploration methods are limited by the tremendous amounts of substrates needed to screen thousands of reactions. A recent paper describes a new technique that miniaturizes and speeds up that process to boost the rate of discovery. This method encapsulates experiments into microfluidic droplets to screen enzymatic reactions. The proof-of-concept study searched for bacterial enzymes that can degrade host glycans. as the breakdown of host glycans can thin the mucus layer in IBD. Using this method, the researchers identified several degradative pathways that are prevalent in IBD patients all at a rate 2,600 times faster than current screening methods allow. While it remains to be seen whether these differences are a cause or consequence of IBD this method could offer a much needed boost in experimental efficiency across the fields of medicine, synthetic biology, and environmental research. 